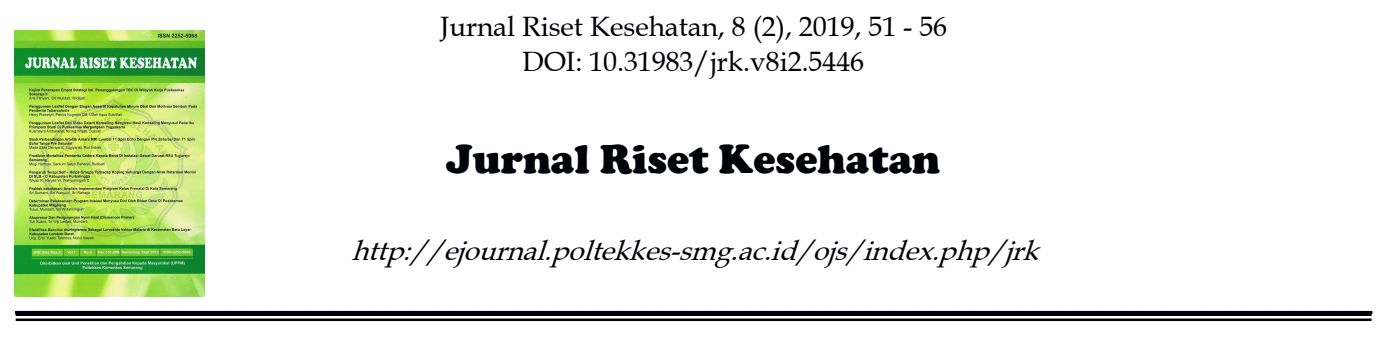

\title{
DIFFERENCE OF THE IMAGE INFORMATION AXIAL PELVIC MRI USING DIFFUSION WEIGHTED IMAGE SEQUENCE WITH THE VARIATION OF B VALUE IN CERVICAL CANCER
}

\author{
Rini Indrati ${ }^{{ }^{*}}$; Distyarini Primadita ${ }^{\mathrm{b}}$; Widiana Ferriastutic ${ }^{\mathrm{c}}$; Marichatul \\ Jannah $^{\mathrm{d}}$ 'Sri Mulyati ; Siti Daryatif \\ a,deff Poltekkes Kemenkes Semarang; Tirto Agung Pedalangan ; \\ Semarang 50268 ; Indonesia \\ b,c Dr. Soetomo Hospital ; Mayjen Prof. Dr. Moestopo ; Surabaya 60285 ; Indonesia
}

\begin{abstract}
Cervical cancer is the second most common type of cancer worldwide, it is reaching $15 \%$ of all kind of cancer in women. There are several ways to diagnose cervical cancer, one of them is an MRI. One of the MRI sequences which can perform the pathology of cervical cancer is Diffusion-Weighted Image. The aim of this research is to find out the anatomical differences between axial slice image of Pelvic MRI which is using DWI sequence with the variation of $b$ value in the case of cervical cancer, and also to reveal the optimal $b$ value to obtain the image of Pelvic MRI which is using DWI sequence in the case of cervical cancer. The method of this research is experimental with the comparison of static groups. Data is 30 images of axial DWI Pelvic MRI from 10 patients in the case of cervical cancer with 3 different variations of $b$ value, which are $600 \mathrm{~s} / \mathrm{mm}^{2}, 800 \mathrm{~s} / \mathrm{mm}^{2}$, and 1000 $\mathrm{s} / \mathrm{mm}^{2}$. Assessment of information image data done by the radiologist. Data analysis by Friedman and Wilcoxon Test. The result showed that there are differences of image information between axial Pelvic MRI which is using the DWI sequence with the variation of $b$ value in the case of cervical cancer with a significant $p$-value $<0.001$. Differences in image information occur in the tumor, expansion of tumor, parametrium until the pelvic wall and lymph. The optimal use of $b$ value for axial Pelvic MRI with DWI sequence in the case of cervical cancer is $600 \mathrm{~s} / \mathrm{mm}^{2}$.
\end{abstract}

Keywords: pelvic mri ; diffusion-weighted image ; b value ; cervical cancer

\section{Introduction}

Cervical cancer is the second most common cancer in the world that reaches $15 \%$ of all cancers in women (Mustari, 2006). Cervical cancer is cancer that occurs in the cervical area, which is the area of the female reproductive organs that is the entrance to the uterus, located between the uterus (uterus) with the female copulation (vagina) (Wijaya, 2010), (Diananda, 2019). To establish a diagnosis in cases of cervical cancer can be done in several ways one of them by examining Magnetic Resonance Imaging (MRI). Magnetic Resonance Imaging is a radiological technique that uses magnetization, radiofrequency, and computers to produce a

\footnotetext{
*) Corresponding Author (Rini Indrati)

E-mail: riniindrati@poltekkes-smg.ac.id
}

picture of body structure. Magnetic resonance imaging was used for clinical examination beginning in 1982 and was used on the nervous system examination (Worthington, 2001). At this time MRI continues to grow and play a lot in various examinations for both cases of tumors, as well as other cases (Bruegel, 2008).

To get a precise image it is necessary to set appropriate parameters and sequences. In the case of cervical cancer, MRI images with high contrast are required, such contrast can be used as early data of cancer determination. One of the MRI sequences that can tell the image of cervical cancer is Diffusion Weighted Image (DWI) (Moeller, 2003). Initially, the DWI sequence was used as a routine sequence of head MRI examinations to detect changes that occur early on after a stroke, such as the restriction of fluid 
diffusion (Bammer, 2003). In its development, the DWI sequence is also used on examinations other than head MRI, as in MRI pelvis (Blink 2004). DWI sequences on MRI pelvis are used to help localize the location of cancer and its extent. The sensitivity of diffusion is controlled by the parameter of $b$ value (Hagmann, 2006). B value determines the diffusion attenuation by modifying the duration and amplitude of the diffusion gradient. B value is denoted by $\mathrm{s} / \mathrm{mm} 2$. The range of $b$ values is $500 \mathrm{~s} / \mathrm{mm}^{2}$ to 1500 $\mathrm{s} / \mathrm{mm}^{2}$ (Westbrook Catherine, Kaut Carolyn \& Talbot John, 2011). In some hospitals for MRI, the DWI sequence pelvis exists using the parameter value of $600 \mathrm{~s} / \mathrm{mm}^{2}$, others using the parameter value of $800 \mathrm{~s} / \mathrm{mm}^{2}$.

Diffusion is a term used to describe the movement of water molecules randomly on a network. Imaging with spin-echo sequences can show structures with signs of diffusion on the network. The diffusion picture can be obtained more effectively by combining the two gradient pulses applied after excitation. In the illustration of diffusion of attenuated signals occurs in normal tissue with random diffusion movement, so that normal tissue will appear darker. High-intensity signals occur in tissues with limited diffusion (restriction) eg in acute and hyper acute ischemic strokes (Hornak, 2011).

The amount of attenuation depends on the amplitude and direction of the diffusion gradient application. The diffusion direction on the $X, Y$, and $Z$ axes are combined to produce a weighted diffusion image. When the diffusion gradient is applied only along the Y-axis, or in the X-axis direction, the signal changes occur only slightly. (Kuperman, 2000). The term isotropic diffusion is used to illustrate that the diffusion gradient is applied to all three axes. The diffusion gradient must be very long and very strong in order to obtain the image by diffusion weighting. The sensitivity of diffusion is controlled by the parameter of $b$ value. The higher the value of $b$ value, the intensity of the diffusion signal and the diffusion sensitivity will increase, the intensity of the increased diffusion signal in the normal brain tissue will appear darker on the displayed brain image. An assessment of the intensity of diffusion signals in normal brain tissue is assessed in white matter and gray matter and if there is a stroke abnormality the limited brain tissue will produce a signal intensity that is visibly brighter than normal tissue.

Apparent Diffusion Coefficient (ADC) is post-processing of DWI by calculating 3 sets of DWI that have different $b$ values. The calculation results will be displayed in the form of ADC value, where the ischemic region will give a picture of hypo intense (Yoshikawa, 2006). The clinical application of direct diffusion imaging is to diagnose a stroke (Zafer, 2014). Early ischemic lesions may be demonstrated by imaging For diffusion imaging when using a multishot sequence the phase change will be different for different lines in $\mathrm{K}$ space and this will produce artifacts visible along with the direction phases. For this reason, the MRI image with diffusion weighting is generally obtained by the SE-EPI technique performed with a strong gradient.

The addition of DWI sequences to MRI Pelvis with cases of cervical cancer is to detect and assess the characteristics of lesions to assess the stage of malignancy. Cervical cancer shows lower ADC values (more limited diffusion) than normal cervical tissue, thus enhancing DWI imaging power. A lower ADC value is obtained when using a higher $\mathrm{b}$ value.

\section{Method}

This research is quantitative research of experimental approach with static group comparison (a Static Group Comparison) aimed to know the difference of MRI Pelvis image with the change of $b$ value of diffusion-weighted image sequence in a cervical cancer case. The population in this study were all pelvic MRI examination in patients with cervical cancer in the radiology unit of RSUD Dr. Soetomo Surabaya while the sample of the research was 10 patients with cervical cancer, then each of the samples from this research was done DWI scanning with 3 variation $\mathrm{b}$ value that is 600 $\mathrm{s} / \mathrm{mm}^{2}, 800 \mathrm{~s} / \mathrm{mm}^{2}$ and $1000 \mathrm{~s} / \mathrm{mm}^{2}$.

Respondents who assessed the MRI image of the pelvis of DWI sequence axial chunks with variation $b$ values were radiology specialists. Image information in this research is the result of observation on image quality. The image quality referred to in this study refers to the image of anatomy and image contrast in general with ordinal measurement scale measured using checklists assessed by the radiologist. The selected image is axial slice pieces and arranged without any identity and description $b$ value then stored in the CD with DICOM format then displayed in the computer doctor radiology to examine the diagnostic description of each patient one by one. Qualitative research in terms 
of assessing image contrast in general and image information: tumor, expansion of tumor, parametrium to the pelvic wall and lymph nodes. And choose the best image of 10 samples with variation $b$ value.

Data from the results of the assessment in the questionnaire were tested by Cohens' Kappa as a parameter of the subjective consistency of respondents. The results of questionnaires Radiologists obtained from the comparison of three variations of $b$ value of sequence diffusion-weighted image sequence on MRI pelvis are ordinal data. To determine the optimal $b$ value to produce the pelvic MRI image in axial fragments in the case of cervical cancer, a Friedman and Wilcoxon test is performed by looking at the highest mean rank values of each variation of the $b$ value used, as well as for determining the effective $b$ value to produce the optimal image. To find out the difference in the pelvic MRI image information to the variation of b value.

\section{Result and Discussion}

Friedman test aims to know the difference of variation of $b$ value to image information of MRI Pelvis sequence DWI axial pieces. The results of Friedman test on each variation are as follows

Table 1. Result of Difference Image Information $a t b$ value variation with Friedman Test.

\begin{tabular}{cc}
\hline Variable & p-value \\
\hline Image Information with $\mathrm{b}$ value & $<0.001$ \\
variation $\left(600,800\right.$ and $\left.100 \mathrm{~s} / \mathrm{mm}^{2}\right)$ & \\
\hline
\end{tabular}

From the results of friedman test for the whole organs in each variation is $p<0.001$ which is $p<0.05$ which means there is a difference in each variation for the whole organ. Then performed continuing Test with Wilcoxon is a follow-up test of Friedman test that aims to determine the differences of each variation of the Pelvis MRI image information as a whole.

Table 2. Result of Difference Image Information at $b$ value variation with Wilcoxon test.

\begin{tabular}{ll}
\hline \multicolumn{1}{c}{ Variable } & p-value \\
\hline $\begin{array}{l}\text { Image Information with } \mathrm{b} \text { value } 600 \\
\mathrm{~s} / \mathrm{mm}^{2} \text { vs b value } 800 \mathrm{~s} / \mathrm{mm}^{2}\end{array}$ & $<0.001$ \\
\hline $\begin{array}{l}\text { Image Information with } \mathrm{b} \text { value } 600 \\
\mathrm{~s} / \mathrm{mm}^{2} \text { vs b value } 1000 \mathrm{~s} / \mathrm{mm}^{2}\end{array}$ & $<0.001$ \\
\hline $\begin{array}{l}\text { Image Information with } \mathrm{b} \mathrm{value} 800 \\
\mathrm{~s} / \mathrm{mm}^{2} \text { vs b value } 1000 \mathrm{~s} / \mathrm{mm}^{2}\end{array}$ & $<0.001$ \\
\hline
\end{tabular}

Based on the test with Wilcoxon if the value of significance $p$-value of each variation is smaller than $\alpha=0.05$, then Ho is rejected, that there is a difference in each variation of $b$ value to the MRI image information Pelvis DWI sequence of axial pieces. In determining the value of optimal $b$ value can be known by looking at the mean rank value on the Friedman test.

Table 3. Difference test for all organs in each variation Results with Friedman test results for

\begin{tabular}{lc}
\hline \multicolumn{1}{c}{ Variable } & Mean Rank \\
\hline $\begin{array}{l}\text { Image Information with b value } \\
600 \mathrm{~s} / \mathrm{mm}^{2}\end{array}$ & 2.80 \\
\hline Image Information $800 \mathrm{~s} / \mathrm{mm}^{2}$ & 1.91 \\
\hline Image Information $1000 \mathrm{~s} / \mathrm{mm}^{2}$ & 1.29
\end{tabular}

Based on the mean rank result for the highest value that is at $\mathrm{b}$ value $600 \mathrm{~s} / \mathrm{mm}^{2}$ with mean rank 2,80, second rank at $b$ value 800 $\mathrm{s} / \mathrm{mm}^{2}$ with mean rank 1,91 and last rank at $\mathrm{b}$ value $1000 \mathrm{~s} / \mathrm{mm}^{2}$ with mean Rank 1.29. Judging by the mean rank values for the best results outcome based on the overall Friedman test is $b$ value $600 \mathrm{~s} / \mathrm{mm}^{2}$, while the lowest result is $b$ value $1000 \mathrm{~s} / \mathrm{mm}^{2}$.

After Friedman test on the whole organ, Friedman test on each organ, to know the difference of variation of $b$ value to image information of MRI Pelvis DWI sequence of axial pieces in case of cervical cancer. The results of the Friedman test on each organ are as follows.

Table 4. Results Mean Rank and significance of Friedman test Variation of $b$ value to MRI Pelvis sequence DWI axial cuts of cases of cervical cancer in each organ.

\begin{tabular}{lccc}
\hline \multicolumn{1}{c}{ Organ } & $\begin{array}{c}\text { B Value } \\
\left(\mathrm{s} / \mathrm{mm}^{2}\right)\end{array}$ & p-value & Mean rank \\
\hline Tumor & 600 & & 2.85 \\
& 800 & $<0.001$ & 1.35 \\
& 1000 & & 1.30 \\
\hline Expansion of & 600 & & 2.85 \\
Tumors & 800 & $<0.001$ & 1.35 \\
& 1000 & & 1.30 \\
\hline Parametrium & 600 & & 2.65 \\
- pelvic wall & 800 & $<0.004$ & 2.05 \\
& 1000 & & 1.30 \\
\hline Lymph & 600 & & 2.85 \\
nodes & 800 & $<0.001$ & 1.90 \\
& 1000 & & 1.25 \\
\hline
\end{tabular}


Based on the Friedman test table on each organ every variation that is on tumor organs, for the highest mean rank that is on $b$ value 600 $\mathrm{s} / \mathrm{mm}^{2}$ with the value of 2.85 , then the second position is on $\mathrm{b}$ value $800 \mathrm{~s} / \mathrm{mm}^{2}$ with a mean value of 1,35 and last on $b$ value of $1000 \mathrm{~s} / \mathrm{mm}^{2}$ with mean rank 1.30. The value of $p$ value of variation $b$ value in tumor is $<0.001$, which means there is difference between each variation of tumor image information.

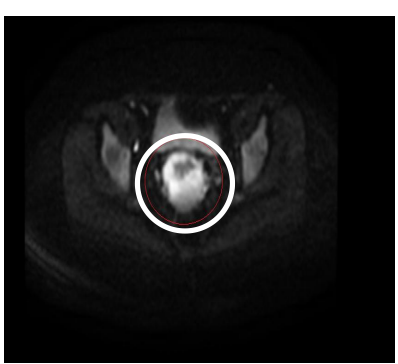

(a)

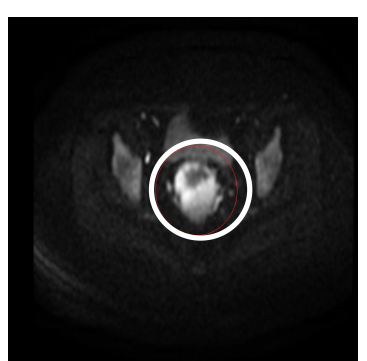

(b)

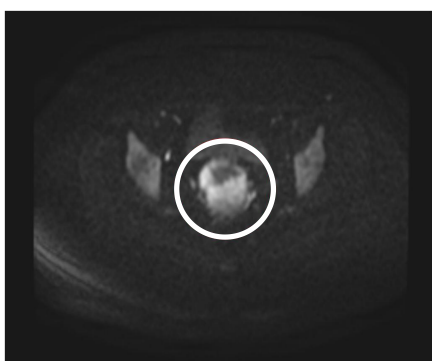

(c)

Figure 1. The axial section of DWI MRI Pelvis sequence with variation (a) $b$ value of $600 \mathrm{~s} / \mathrm{mm}^{2}$,

(b) $b$ value $800 \mathrm{~s} / \mathrm{mm}^{2}$ and (c) b value 1000

$s / \mathrm{mm}^{2}$ on tumor image and tumor extension.

The highest mean tumor extension was on $\mathrm{b}$ value of $600 \mathrm{~s} / \mathrm{mm}^{2}$ ie 2.85 , the second rank at b value $800 \mathrm{~s} / \mathrm{mm}^{2}$ with mean rank 1.35 and last with $\mathrm{b}$ value $1000 \mathrm{~s} / \mathrm{mm}^{2}$ with mean rank 1,30. For $\mathrm{p}$-value that is $<0.001$ which means there is a difference in each variation to information of tumor expansion image.

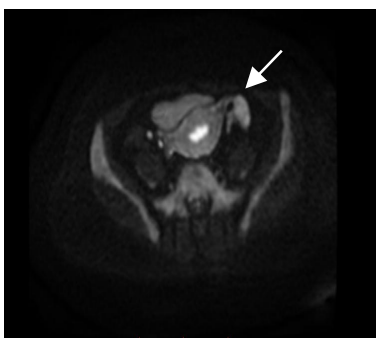

(a)

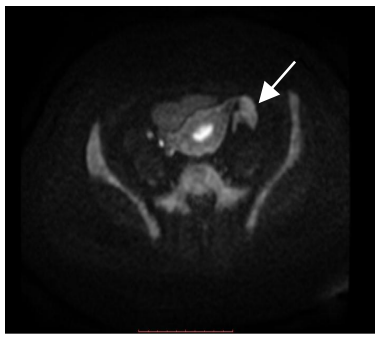

(b)

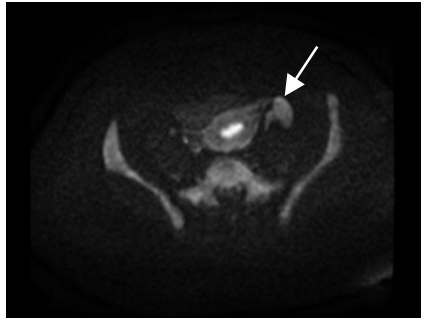

(c)

Figure 2. Pieces of axial DWI MRI Pelvis sequence with variations (a) $b$ value of 600 $\mathrm{s} / \mathrm{mm}^{2}$, (b) $b$ value of $800 \mathrm{~s} / \mathrm{mm}^{2}$ and (c) $b$ value of $1000 \mathrm{~s} / \mathrm{mm}^{2}$ in the parametric image up to the pelvic wall.

In Parametrium up to the highest mean rectangle wall value is at $b$ value of $600 \mathrm{~s} / \mathrm{mm} 2$ ie 2.65 , second rank at $b$ value $800 \mathrm{~s} / \mathrm{mm}^{2}$ with mean rank 2.05 and last with $b$ value 1000 $\mathrm{s} / \mathrm{mm}^{2}$ with mean rank 1.30 . For $\mathrm{p}$-value that is < 0.001 which means there is a difference in each variation to information of parametrium image up to the pelvic wall.

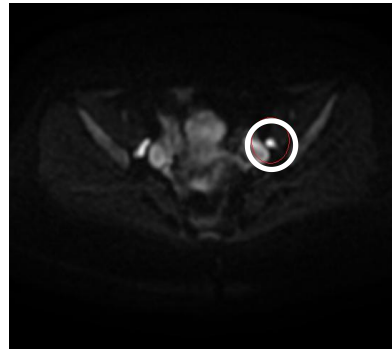

(a)

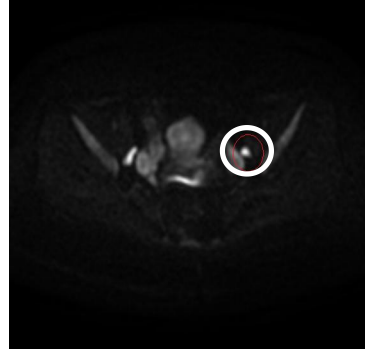

(b)

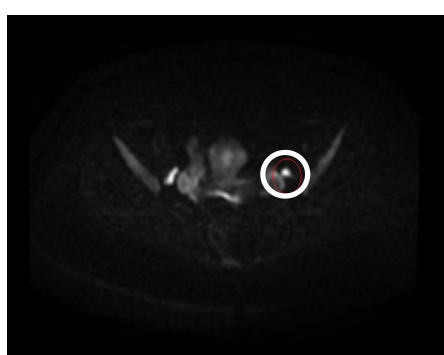

(c)

Figure 3. The axial chunks of DWI MRI Pelvis sequence with variations (a) $b$ value of 600 $\mathrm{s} / \mathrm{mm}^{2}$, (b) $b$ value of $800 \mathrm{~s} / \mathrm{mm}^{2}$ and (c) $b$ value of $1000 \mathrm{~s} / \mathrm{mm}^{2}$ in the image of the lymph nodes.

In Lymph nodes the highest mean rank is at $b$ value $600 \mathrm{~s} / \mathrm{mm}^{2}$ that is 2.85 , second rank at $\mathrm{b}$ value $800 \mathrm{~s} / \mathrm{mm}^{2}$ with mean rank 1.90 and last with $\mathrm{b}$ value $1000 \mathrm{~s} / \mathrm{mm}^{2}$ with mean rank 1.25. For p-value that is $<0.001$ which means there is a difference in each variation to information of the image of lymph nodes.

Based on Friedman's test results to know 
the difference to the variation of $b$ value, for the value of $600 \mathrm{~s} / \mathrm{mm}^{2}, 800 \mathrm{~s} / \mathrm{mm}^{2}$ and $1000 \mathrm{~s} / \mathrm{mm}^{2}$ with the value of $\rho<0.001$ which means there are significant differences or $\mathrm{Ha}$ accepted. Differences in the intensity of diffusion signals in MRI Pelvis sequences of DWI sequences are caused by the influence of parameter selection of $b$ value on the signal intensity (Hagmann, 2006) . Differences in the intensity of diffusion signals in MRI Pelvis sequences of DWI sequences are caused by the effect of $b$ value parameter selection on signal intensity of diffusion. This is consistent with the theory that the selection of the ' $b$ ' value parameter will affect the intensity of the diffusion signal and the sensitivity of the diffusion (Westbrook Catherine, Kaut Carolyn \& Talbot John, 2011). The sensitivity of diffusion is the ability to distinguish the diffusion abnormalities in normal tissue or to detect the diffusion that is limited to abnormal tissue. If the intensity of the diffusion signal gets stronger then the normal network diffusion image will appear darker and the abnormally diffuse unfocused tissue will appear bright on the image. If the intensity of the diffusion signal is weak, the normal tissue will appear grayish and the abnormally diffuse tissue will appear bright, so the difference between the two is difficult to see clearly because it does not look firmly (Westbrook Catherine, Kaut Carolyn \& Talbot John, 2011).

Based on the result of mean rank on whole organs for each variation of value of $b$ value that is got the highest mean value at value $600 \mathrm{~s} / \mathrm{mm}^{2}$ with mean value 2.80 while lowest is 1000 $\mathrm{s} / \mathrm{mm}^{2}$ with mean rank 1.29 . On the mean rank result on each tumor organs in each variation of value of $b$ value the highest mean rank value that is at $600 \mathrm{~s} / \mathrm{mm}^{2}$ is 2.85 while the last one at the value of $1000 \mathrm{~s} / \mathrm{mm}^{2}$ with the value of 1.30 , for the mean rank value Highest on the Tumor Expansion is at the value of $600 \mathrm{~s} / \mathrm{mm}^{2}$ is 2.85 , then on Parametrium to the highest mean pelvis mean wall is at $600 \mathrm{~s} / \mathrm{mm}^{2}$ with a mean value of 2.65. In the lymph nodes are also the same, the highest mean rank value is $600 \mathrm{~s} / \mathrm{mm}^{2}$, with a mean value of 2.85. According to Zefer Koc et al (2014), the higher the value of $b$ value, the restricted lesion area is more visible, but the image quality will decrease and the noise will be more in comparison with the lower $b$ value. According to Dietrich et al (2008) the addition of a high-value $b$ value will result in a more noise image, which would be difficult to evaluate the ADC if the noise level does not match the signal.
Therefore to determine the optimal value of $b$ value must also consider the noise level (Yoshikawa, 2006).

The above research shows that in $b$ value $1000 \mathrm{~s} / \mathrm{mm}^{2}$ produces the image with the highest intensity of diffusion signal so that the normal appearance of the surrounding tissue becomes darkest and there is a lot of noise, only visible contrast of tissue with limited diffusion (cancer). According to Zafer Koc et al, (2014). DWI sequences should be optimized to maximize SNR and reduce artifacts to produce good image quality. Increasing $\mathrm{b}$ value can decrease SNR. Noise can be minimized by using $b$ values that are not too high. In the selection of $b$ value 800 $\mathrm{s} / \mathrm{mm}^{2}$ the intensity of the resulting diffusion signal is not very high, so the normal network image around and contrast of the limited diffusion tissue (cancer) is visible but the limit is not clear. While in the selection of $b$ value 600 $\mathrm{s} / \mathrm{mm}^{2}$ the intensity of the diffusion signal is the lowest so that the surrounding tissue image is still clearly visible and the contrast in the limited diffusion network (cancer) is also clear. The boundaries of the organs are clearly visible. According to Zefer Koc et al. (2014) TE must remain short in order to correct the decrease of SNR caused by high b value. B value $600 \mathrm{~s} /$ $\mathrm{mm} 2$ has the shortest TE, so the SNR of $b$ value $600 \mathrm{~s} / \mathrm{mm} 2$ is the best.

Based on these results than for the best variation of $b$ values that is on the first variation with the value of $b$ value $600 \mathrm{~s} / \mathrm{mm}^{2}$.

\section{Conclusion and Suggestion}

There are differences in the axial image information of MRI Pelvis sequence of Diffusion-Weighted Image on cervical cancer using MRI 1.5 Tesla plane with the variation of $b$ value $600 \mathrm{~s} / \mathrm{mm}^{2}, 800 \mathrm{~s} / \mathrm{mm}^{2}$ and $1000 \mathrm{~s} / \mathrm{mm}^{2}$.

The best image information MRI sequence axial slice of Diffusion-Weighted Image sequence is in the selection of $\mathrm{b}$ value of $600 \mathrm{~s} / \mathrm{mm}^{2}$, the second is with $\mathrm{b}$ value $800 \mathrm{~s} / \mathrm{mm}^{2}$ and the image of the Pelvis axial MRI with the lowest image information is at $\mathrm{b}$ value $1000 \mathrm{~s} / \mathrm{mm}^{2}$. For MRI examination in cervical cancer cases it is recommended to use a b value of $600 \mathrm{~s} / \mathrm{mm}^{2}$.

\section{Acknowledgements}

Thank you to the Director of Poltekkes Kemenkes Semarang for the research activities. Thank you also to the Director of RS Soetomo Hospital Surabaya for permission to conduct 
research, especially the Radiology Installation for assistance at the time of data collection.

\section{References}

Blink. Evert, J., 2004, Basic MRI Physics, www.mri-physics.net.

Bammer R. Basic principles of diffusion-weighted imaging. Eur J Radiol 2003;45:169-184.

Bruegel M, Gaa J, Waldt S, et al. Diagnosis of hepatic metastasis: comparison of respiration-triggered diffusion-weighted echoplanar MRI and five T2-weighted turbo spin-echo sequences. Am J Roentgenol 2008;191:1421-1429.

Diananda, 2009, Mengenal Seluk - Beluk Kanker, Yogjakarta: Katahati.

Dietrich Olaf et al. Magnetic resonance noise measurements and signal-quantization effects at very low noise levels. Magn Reson Med 2008;60:1477-1487.

Hagmann P, Jonasson L, Maeder P, Thiran JP, Wedeen VJ, Meuli R. Understanding diffusion MR imaging techniques: from scalar diffusion-weighted imaging to diffusion tensor imaging and beyond. Radiographics 2006;26(Suppl 1):205-223.

Hornak, J.P., 2011, The Basics of MRI Interactive Learning Software, Henietta: New York.
Kuperman, Vadim., 2000, Magnetic Resonance Imaging, Physical Principles And Application, United States Of America. Academic Press.

Moeller, Torsten B. M. D., 2003, MRI Parameters and positioning, Am caritas krankehaus billingen/saar, New York.

Mustari., 2006, Kanker leher Rahim, http://hgBKKBN/artikel/htm.

Wijaya., 2010, Pembunuh Ganas Itu Bernama Kanker Serviks, Yogyakarta: Niaga Swadaya.

Westbrook, Catherine. Roth, Carolyn, Kaut. \& Talbot, John., 2011. MRI in Pratice Fourth Edition, United Kingdom, Wiley Blackwell.

Worthington, Brian S., 2001, Magnetic Resonance Imaging, http:/ / onlinelibrary.wiley.com.

Yoshikawa T, Kawamitsu H, Mitchell DG, et al. ADC measurement of abdominal organs and lesions using parallel imaging technique. Am J Roentgenol 2006;187:1521-1530.

Zafer Koc, MD,* and Gurcan Erbay, MD OptimalbValue in Diffusion-Weighted Imagingfor Differentiation of Abdominal Lesions, Journal Of Magnetic Resonance Imaging 40:559-566 (2014). 